\title{
Association Between Employment Status and Objectively Measured Physical Activity and Sedentary BehaviorThe Maastricht Study
}

Citation for published version (APA):

Pulakka, A., Stenholm, S., Bosma, H., Schaper, N. C., Savelberg, H. H. C. M., Stehouwer, C. D. A., van der Kallen, C. J. H., Dagnelie, P. C., Sep, S. J. S., \& Koster, A. (2018). Association Between Employment Status and Objectively Measured Physical Activity and Sedentary BehaviorThe Maastricht Study. Journal of Occupational and Environmental Medicine, 60(4), 309-315.

https://doi.org/10.1097/JOM.0000000000001254

Document status and date:

Published: 01/04/2018

DOI:

10.1097/JOM.0000000000001254

Document Version:

Publisher's PDF, also known as Version of record

Document license:

Taverne

Please check the document version of this publication:

- A submitted manuscript is the version of the article upon submission and before peer-review. There can be important differences between the submitted version and the official published version of record.

People interested in the research are advised to contact the author for the final version of the publication, or visit the DOI to the publisher's website.

- The final author version and the galley proof are versions of the publication after peer review.

- The final published version features the final layout of the paper including the volume, issue and page numbers.

Link to publication

\footnotetext{
General rights rights.

- You may freely distribute the URL identifying the publication in the public portal. please follow below link for the End User Agreement:

www.umlib.nl/taverne-license

Take down policy

If you believe that this document breaches copyright please contact us at:

repository@maastrichtuniversity.nl

providing details and we will investigate your claim.
}

Copyright and moral rights for the publications made accessible in the public portal are retained by the authors and/or other copyright owners and it is a condition of accessing publications that users recognise and abide by the legal requirements associated with these

- Users may download and print one copy of any publication from the public portal for the purpose of private study or research.

- You may not further distribute the material or use it for any profit-making activity or commercial gain

If the publication is distributed under the terms of Article $25 \mathrm{fa}$ of the Dutch Copyright Act, indicated by the "Taverne" license above, 


\title{
Association Between Employment Status and Objectively Measured Physical Activity and Sedentary Behavior-The Maastricht Study
}

\author{
Anna Pulakka, PhD, Sari Stenholm, PhD, Hans Bosma, PhD, Nicolaas C. Schaper, MD, PhD, \\ Hans H.C.M. Savelberg, PhD, Coen D.A. Stehouwer, MD, PhD, Carla J.H. van der Kallen, PhD, \\ Pieter C. Dagnelie, PhD, Simone J.S. Sep, PhD, and Annemarie Koster, PhD
}

\begin{abstract}
Objective: To examine the association between employment status and physical activity and sedentary behavior. Methods: We included 2045 participants from The Maastricht Study, who used a thigh-worn accelerometer. We compared time spent sedentary, standing, stepping, and higher intensity physical activity between participants with different employment status (non-employed or low-, intermediate- or high-level occupation) with analysis of variance. Results: Participants in low-level occupations were less sedentary and standing and stepping more than those in other occupational categories and non-employed participants. Among the employed, the differences were mostly observed on weekdays, whereas the differences in sedentary time and standing between those in low-level occupations and nonemployed participants were evident both on weekdays and weekend days. Conclusions: Those in low-level occupational category were less sedentary and more active than non-employed and those in other occupational categories, especially on weekdays.
\end{abstract}

Keywords: accelerometer, activity domains, employment, physical activity, sedentary behavior, work

From the Department of Public Health, University of Turku and Turku University Hospital, Turku, Finland (Dr Pulakka, Dr Stenholm); Care and Public Health Research Institute (Dr Bosma, Dr Schaper, Dr Dagnelie, Dr Koster); Department of Social Medicine (Dr Bosma, Dr Koster); School for Cardiovascular Diseases (Dr Schaper, Dr Stehouwer, Dr van der Kallen, Dr Dagnelie, Dr Sep); Department of Human Movement Sciences (Dr Savelberg); School for Nutrition and Translational Research in Metabolism (Dr Savelberg); Department of Epidemiology (Dr Dagnelie), Maastricht University; and Department of Internal Medicine, Maastricht University Medical Centre (Dr Schaper, Dr Stehouwer, Dr van der Kallen, Dr Sep), Maastricht, the Netherlands.

Funding: This study was supported by the European Regional Development Fund via OP-Zuid, the Limburg Provincial Government, the Dutch Ministry of Economic Affairs (grant 310.041), Stichting De Weijerhorst (Maastricht, the Netherlands), the Parelsnoer Diabetes Initiative (Amsterdam, the Netherlands), the Cardiovascular Center (CVC, Maastricht, the Netherlands), CARIM School for Cardiovascular Diseases (Maastricht, the Netherlands), CAPHRI Care and Public Health Research Institute (Maastricht, the Netherlands), NUTRIM School for Nutrition and Translational Research in Metabolism (Maastricht, the Netherlands), Stichting Annadal (Maastricht, the Netherlands), Health Foundation Limburg (Maastricht, the Netherlands) and by unrestricted grants from Janssen-Cilag B.V. (Tilburg, the Netherlands), Novo Nordisk Farma B.V. (Alphen aan den Rijn, the Netherlands) and Sanofi-Aventis Netherlands B.V. (Gouda, the Netherlands) The study was also supported by the Academy of Finland (projects 286,294 and 294,154 for S.S.).

Authors Pulakka, Stenholm, Bosma, Schaper, Savelberg, Stehouwer, van der Kallen, Dagnelie, Sep, and Koster have no relationships/conditions/circumstances that present potential conflict of interest.

The JOEM editorial board and planners have no financial interest related to this research.

Supplemental digital contents are available for this article. Direct URL citation appears in the printed text and is provided in the HTML and PDF versions of this article on the journal's Web site (www.joem.org).

Address correspondence to: Anna Pulakka, PhD, Department of Public Health, University of Turku and Turku University Hospital, Joukahaisenkatu 3-5, FI20014 Turku, Finland (anna.pulakka@utu.fi).

Copyright (C) 2018 American College of Occupational and Environmental Medicine

DOI: 10.1097/JOM.0000000000001254

\section{Learning Objectives}

- Discuss current knowledge of changes in occupation-related physical activity and sedentary time, including differences by occupational level.

- Summarize the new findings on sedentary time and physical activity by occupational level, including any differences for working days versus weekend days.

- Discuss the implications for interventions to address physical activity and sedentary behavior.

D hysical inactivity and sedentary behavior can occur in three activity domains, namely work, leisure, and transport. ${ }^{1,2}$ They represent independent risk factors for adverse health outcomes such as coronary heart disease and type 2 diabetes. ${ }^{2-4}$ Although occupation-related physical activity has decreased markedly in recent decades, ${ }^{5}$ it is still estimated that work accounts for about $40 \%$ of the time spent in moderate-to-vigorous physical activity. ${ }^{6}$ On the other hand, work done in sitting position has become very common ${ }^{7}$ and among those with sedentary jobs, work can greatly contribute to total daily sitting time. ${ }^{8}$

Levels of physical activity and sedentariness vary between different socioeconomic and occupational level categories. Several studies have shown that highly educated people and those with high income spend more total or leisure time in physical activity than people with lower education or income. ${ }^{1,9,10}$ However, when occupational level is used as a measure of socioeconomic status, the association becomes less clear ${ }^{10}$ or is even reversed, with people in the lower-level occupational levels accumulating more total physical activity than people in the high-level occupational category. ${ }^{11}$

The literature on physical activity and sedentary behavior across different socioeconomic or occupational categories has mostly relied on self-reported measures, ${ }^{9-11}$ which have low precision and are prone to bias. ${ }^{12,13}$ Furthermore, non-working adults, who form a large part of the general population, have typically been excluded from these studies. ${ }^{9}$ Excluding the non-employed could lead to underestimation of occupational differences, since non-working adults often belong to the lower-level occupational categories. ${ }^{14}$

A few studies have reported objectively measured physical activity and sedentary behavior on weekdays and weekend days in relatively small samples of specific occupational groups, such as office $^{8,15-18}$ or construction ${ }^{13}$ workers or both, ${ }^{19}$ office and customer service employees, ${ }^{20}$ nurses $^{21}$ or police officers. ${ }^{22}$ One study investigated objectively measured occupational activity for self-reported occupational categories in a nationally representative sample, but it did not focus on differences between weekdays and weekend days. ${ }^{23}$ Thus, there was a need for a study including a large sample of both non-employed and employed participants from various occupations and including measurements on weekdays and weekend days.

To address this gap in the literature, we used 7-day measurements with thigh-worn activPAL3 ${ }^{\mathrm{TM}}$ (PAL Technologies, Glasgow, UK) accelerometers in a large sample that included both 
non-employed and employed people. The aim of the study was to examine the association between employment status and objectively measured sedentary behavior and physical activity, on average days as well as on weekdays and weekend days. We also examined the differences in activity levels between week and weekend days within and between employment statuses, using weekdays to approximate physical activity during working days and weekend days to estimate physical activity during non-working days. Our hypothesis was that those in the low-level occupational category would accrue less sedentary time and more physical activity on weekdays than those in higher-level occupational categories whereas those in the high-level occupational category would engage in more physical activity on weekend days than those in low-level occupational category.

\section{METHODS}

\section{Participants}

We used data from The Maastricht Study, a prospective population-based observational cohort study. The rationale and methodology have been described elsewhere. ${ }^{24}$ Briefly, the study focuses on the etiology, pathophysiology, complications and comorbidities of type 2 diabetes mellitus (T2DM) and is characterized by an extensive phenotyping approach. Eligible for participation were all individuals aged between 40 and 75 years and living in the southern part of the Netherlands. Participants were recruited through mass media campaigns and from the municipal registries and the regional Diabetes Patient Registry via mailings. Recruitment was stratified according to known T2DM status, with an oversampling of individuals with T2DM, for reasons of efficiency.

The present report includes cross-sectional data from the first 2778 participants, who completed the baseline survey between November 2010 and September 2013 and who were offered accelerometers. The examinations of each participant were performed within a time window of 3 months. We excluded participants who had missing information on non-employment subgroup, occupational category, or the covariates (age, sex, diabetes status, and presence of mobility limitations, $n=501$ ) or who did not have a minimum of 4 valid days of accelerometer data $(n=232)$, leaving 2045 people in the analyses. The study has been approved by the institutional medical ethics committee (NL31329.068.10) and the Minister of Health, Welfare and Sports of the Netherlands (Permit131088-105234PG). All participants gave written informed consent.

\section{Assessment of Physical Activity and Sedentary Behavior}

Daily activity levels were measured using the activPAL $3^{\mathrm{TM}}$ physical activity monitor (PAL Technologies). The activPAL $3^{\mathrm{TM}}$ is a small $(53 \times 35 \times 7 \mathrm{~mm})$, lightweight $(15 \mathrm{~g})$ triaxial accelerometer that records movements along the vertical, anteroposterior and mediolateral axes, and also determines posture (sitting or lying, standing, and stepping) based on acceleration information. The device was attached directly to the skin on the front of the right thigh with transparent $3 \mathrm{M}$ Tegaderm ${ }^{\mathrm{TM}}$ tape $(3 \mathrm{M}$, St. Paul, MN), after the device had been waterproofed using a nitrile sleeve. Participants were asked to wear the accelerometer for 8 consecutive days, without removing it at any time. To avoid inaccurately identifying non-wear time, participants were asked not to replace the device after they had removed it. Data were uploaded using the activPAL software and processed using customized software written in MATLAB R2013b (MathWorks, Natick, MA). Data from the first day were excluded from the analysis because participants performed physical function tests at the research center after the device was attached. In addition, data from the final wear day providing less than or equal to 14 waking hours of data were excluded from the analysis. Participants were included if they provided at least 4 valid (more than or equal to 10 hours of waking data) days, including minimum of 1 valid weekday and 1 valid weekend day.

The total sedentary time was based on the sedentary postures (sitting or lying), and calculated as the percentage (\%) of time spent in a sedentary positions during waking time per day. Percentage was used instead of absolute time because waking wear time differed between participants with different employment status and between weekdays and weekend days. The method used to determine waking time has been described elsewhere. ${ }^{25}$ The total standing time was based on the standing posture, and calculated as the proportion of time spent standing during waking time per day. The total amount of stepping was based on the stepping posture, and calculated as the proportion of time spent stepping during waking time per day. Stepping time (physical activity) was further classified into higherintensity physical activity (HPA, \% of minutes with a step frequency more than 110 steps/min during waking time). ${ }^{26}$ The daily means were averaged over all valid days, weekdays (from Monday through Friday), and weekend days (Saturday and Sunday) to obtain the proportion of time spent at each activity level for average days, weekdays, and weekend days.

\section{Assessment of Employment Status}

Employment status was assessed with a questionnaire. Participants were asked to classify their current employment status as self-employed, working for the government, salaried worker, disabled, rentier, retired, homemaker, unemployed, or "other." Those who selected the disabled, rentier, retired, homemaker, or unemployed options were classified as currently non-employed. Those in the "other" category were excluded from the analysis because their employment status could not be confirmed. Those who reported being self-employed, salaried workers, or working for the government were further classified as currently employed, and their occupational category was identified based on the question "What category is your job?" and categorized as low (including response options "unskilled" [including, eg, cleaners, waitresses], "skilled" [including, eg, plumbers and construction workers] and "lowerlevel employee"), intermediate or high level, or self-employed.

\section{Covariates}

Age and sex were derived from questionnaires. Diabetes status was assessed by an oral glucose tolerance test. ${ }^{24}$ The presence of mobility limitations (some trouble walking or not able to walk during the past week) or the absence of such limitations (no trouble walking during the past week) was assessed by the EuroQol-5D questionnaire. Level of education was derived from the questionnaires and categorized as low, intermediate, or high. Health behavioral factors were also derived from the questionnaires. Smoking status was categorized as never, former, or current smoker, and alcohol consumption as none, low (less than or equal to 14 or less than or equal to seven alcoholic drinks per week for men and women, respectively) or high (more than 14 or more than 7 alcoholic drinks per week for men and women, respectively). A research assistant measured the participants' body weight and height at the research center, and body-mass index (BMI, $\mathrm{kg} / \mathrm{m}^{2}$ ) was calculated from this information. Frequency of shiftwork was assessed by asking "Did/do you have to work different shifts?".

\section{Data Processing and Analysis}

Normally distributed descriptive variables were summarized as means with standard deviations (SD), variables with skewed distribution as medians and interquartile ranges (IQR) and categorical variables as numbers and percentages. We compared baseline characteristics between non-employed participants and participants in different occupational categories by one-way analysis of variance (ANOVA, continuous, normally distributed variables), KruskalWallis test (continuous variables with skewed distribution) and chisquared test (categorical variables). 
TABLE 1. Descriptive Characteristics of the Study Sample, Stratified by Employment Status

\begin{tabular}{|c|c|c|c|c|c|c|c|}
\hline Variable & $\begin{array}{c}\text { Total } \\
(n=2045)\end{array}$ & $\begin{array}{l}\text { Non-Employed } \\
\quad(n=1200)\end{array}$ & $\begin{array}{l}\text { Low Occupational } \\
\text { Category } \\
(n=110)\end{array}$ & $\begin{array}{c}\text { Intermediate } \\
\text { Occupational } \\
\text { Category }(n=128)\end{array}$ & $\begin{array}{c}\text { High } \\
\text { Occupational } \\
\text { Category }(n=308)\end{array}$ & $\begin{array}{l}\text { Self-Employed } \\
\quad(n=299)\end{array}$ & $\boldsymbol{P}$ \\
\hline Age, mean years (SD) & $60.2(8.0)$ & $64.3(6.3)$ & $53.8(5.9)$ & $54.4(7.0)$ & $53.6(6.0)$ & $55.0(6.3)$ & $<0.0001$ \\
\hline Male sex, n (\%) & $1037(51)$ & $604(50)$ & $60(55)$ & $54(42)$ & $135(44)$ & $184(62)$ & $<0.0001$ \\
\hline Level of education* & & & & & & & $<0.0001$ \\
\hline Low, n (\%) & $650(32)$ & $510(43)$ & $55(50)$ & $19(15)$ & $59(19)$ & $7(2)$ & \\
\hline Intermediate, $\mathrm{n}(\%)$ & $565(28)$ & $285(24)$ & $46(42)$ & $61(48)$ & $131(43)$ & $42(14)$ & \\
\hline High, n $(\%)$ & $819(40)$ & $396(33)$ & $8(7)$ & 47 (37) & $118(38)$ & $250(84)$ & \\
\hline Type 2 diabetes, n (\%) & $534(26)$ & $379(32)$ & $30(27)$ & $23(18)$ & $45(15)$ & 57 (19) & $<0.0001$ \\
\hline Mobility limitation, n (\%) & $316(15)$ & $243(20)$ & $15(14)$ & $15(12)$ & $24(8)$ & $19(6)$ & $<0.0001$ \\
\hline $\begin{array}{c}\text { Number of valid accelerometer } \\
\text { wear days, median (IQR) }\end{array}$ & 7 (6 to 7$)$ & 7 (6 to 7$)$ & 7 (6 to 7$)$ & $6(6$ to 7$)$ & 7 (6 to 7$)$ & 7 (6 to 7$)$ & 0.005 \\
\hline $\begin{array}{l}\text { Daily waking wear time, mean } \\
\text { minutes (SD) }\end{array}$ & $942(53)$ & $934(54)$ & $945(50)$ & $951(51)$ & $955(48)$ & 958 (49) & $<0.0001$ \\
\hline
\end{tabular}

$\mathrm{IQR}$, interquartile range; SD, standard deviation.

${ }^{*}$ Missing information from 11 participants.

First, we compared the time spent sedentary, standing, stepping, and in HPA between non-employed participants and participants in the low-, intermediate-, or high-level occupational categories, on average days during the entire week (ANOVA), on weekdays (repeated measures ANOVA), and weekend days (repeated measures ANOVA), and compared the weekdays and weekend day activity levels within these groups (repeated measures ANOVA). Second, we repeated the analyses focusing on the nonemployed, and examined differences across the non-employed subgroups: retired, homemakers, disabled, unemployed, and rentiers. The results are shown as adjusted means and their $95 \%$ confidence intervals (CI) for the proportion of waking wear time spent being sedentary, standing, stepping, and in HPA. The models were adjusted for age, sex, presence of diabetes, and presence of mobility limitations. We also conducted sensitivity analyses adjusting additionally for (1) education and (2) health behavioral factors: smoking status, alcohol consumption, and BMI. As a third sensitivity analysis to account for uncertainties regarding our assumption that weekdays represented working days and weekend days represented non-working days, we repeated the weekdays versus weekend day comparisons excluding those who were employed and reported doing shiftwork often or always $(n=100)$, or who did not provide information on shiftwork $(n=9)$. Since we found no interactions between sex and overall sedentary time or physical activity, we present all the analyses for men and women combined. All the analyses were performed using SAS 9.4 statistical software (SAS Institute Inc., Cary, NC).

\section{RESULTS}

Table 1 presents the descriptive characteristics of the participants by employment status. Mean (SD) age of all participants was 60.2 (8.0) years, and mean (SD) daily waking wear time over valid days for the entire week was 942 minutes (53). Non-employed participants were generally older and were more likely to have diabetes and mobility limitations than the employed. The 733 participants excluded due to missing information were slightly younger (mean age 59.5 years, SD 8.6), included about equal proportions of men $(53 \%)$, were more likely to have a low educational level $(40 \%)$,

TABLE 2. Percentage of Waking Time, With 95\% Confidence Interval $(\mathrm{Cl})$, Spent Sedentary, Standing, Stepping and in Higher-Intensity Physical Activity on Average Days, Weekdays and Weekend Days by Employment Status

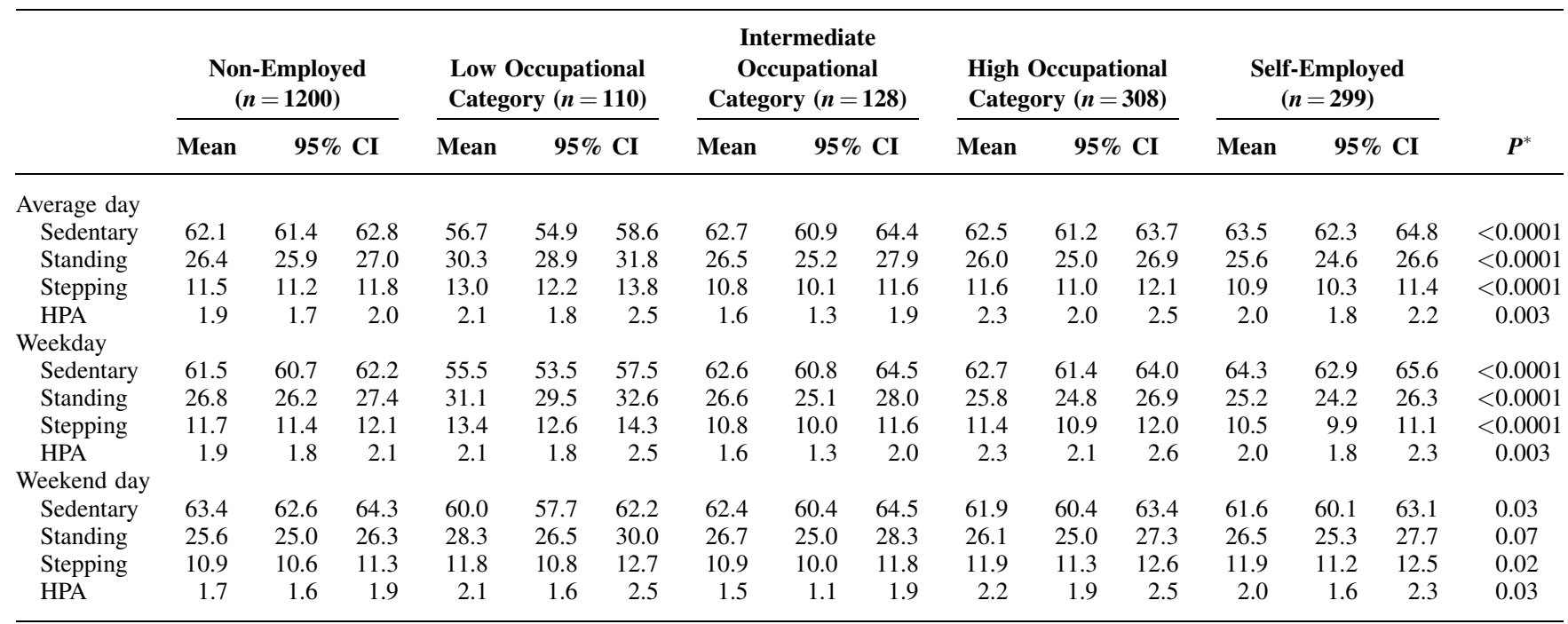

The models have been adjusted for age, sex, presence of diabetes, and presence of mobility limitations. HPA, higher-intensity physical activity.

${ }^{*} P$ value for overall differences between different employment status. 
and were more likely to have diabetes (41\%) and mobility limitations $(21 \%)$ than the 2045 who were included in the analysis.

Time spent sedentary and at different activity levels, stratified by employment status, is presented in Table 2, for average days and for weekdays and weekend days. Overall, those in the low-level occupational category were less sedentary and spent more time standing and stepping than those in other occupational categories and those who were non-employed. Furthermore, those in the highlevel occupational category engaged in more HPA than those in the intermediate occupational category or non-employed participants, although the latter difference was no longer significant in the second sensitivity analysis, adjusting the model additionally for health behavioral factors (Supplemental Digital Content Tables S1 and S2, http://links.lww.com/JOM/A405).

The above differences in total physical activity and sedentary time between employment groups stemmed mostly from weekdays (Table 2). Participants in low-level occupational category were less sedentary and spent more time standing and stepping than those in other occupational categories and non-employed participants on weekdays. In addition, participants in high-level occupational category were more sedentary than non-employed on weekdays, and non-employed participants and those in the high-level occupational category spent more time stepping than self-employed on weekdays. Furthermore, those in the high-level occupational category had more HPA than non-employed participants and those in the intermediate occupational category on weekdays. We observed only few differences on weekend days: those in the low-level occupational category were less sedentary and spent more time standing than nonemployed participants and those in the high-level occupational category had more HPA than those in the intermediate occupational category (Table 2). The main result remained robust in the three sensitivity analyses, with additional adjustments to the models (Supplemental Digital Content Tables S1, S2, http://links. lww.com/JOM/A405) and excluding those who had shiftwork (Supplemental Digital Content Table S3, http://links.lww.com/ $\mathrm{JOM} / \mathrm{A} 405)$ : those in the low-level occupational category were less sedentary and more active than all the other participants on weekdays but not on weekend days.

Physical activity and sedentary time during weekdays and weekend days for each employment status are depicted in Fig. 1, with statistically significant differences marked by an asterisk. Nonemployed participants and those in the low-level occupational category were less sedentary and spent more time standing and stepping during weekdays than during weekend days. Nonemployed participants engaged in more HPA on weekdays than on weekend days. The reverse pattern was observed in the selfemployed and high occupational category participants. Both selfemployed participants and those in high occupational category were more sedentary and spent less time stepping on weekdays than on weekend days. In addition, self-employed participants also spent less time standing on weekdays than on weekend days.

The percentages of time spent sedentary, standing, stepping and in HPA on average days among the non-employed participants are presented in Table 3. Homemakers were less sedentary than retired and disabled participants. In addition, homemakers spent more time standing than retired and disabled participants and rentiers.

\section{DISCUSSION}

In this cross-sectional study, we objectively assessed the time spent sedentary and at different activity levels on weekdays and weekend days, among Dutch adults with different employment status. We found a clear pattern showing that those in the low-level occupational category were less sedentary and more active than all the other groups. Among the employed participants, the differences in activity levels between occupational categories were observed for total time and weekdays, but not for weekend days, suggesting that occupational physical activity was the driving factor of the differences between employed people.

Other studies have also demonstrated that blue-collar workers and those working in retail, ${ }^{27-29}$ construction, ${ }^{19}$ or agriculture ${ }^{30}$ are less sedentary and more active than other employees on working days. In our study, this difference in weekday activity levels was also reflected in total physical activity, which was higher among those in the low-level occupational category than among the others. Similar findings have been reported regarding police officers compared with higher ranking police staff, ${ }^{22}$ retail and blue collar workers compared with office and university workers, ${ }^{29}$ and construction workers compared with employees of financial service providers or research institutes. ${ }^{19}$ Thus, although people with low socioeconomic status generally have poorer health than those with higher status, ${ }^{14,31}$ those in the low-level occupational category may still paradoxically be more physically active and less sedentary than those in the higher-level occupational categories. This emphasises the need for further research into occupational differences in physical activity and sedentary behavior using objective measures. Furthermore, such research should take into account that some types of occupational physical activity, such as heavy lifting, may also be harmful. ${ }^{32-34}$

We did not find differences in activity levels between occupational categories on weekend days. This is in contrast to a systematic review showing that those employed in non-manual occupations had more leisure-time physical activity than those in manual occupations. ${ }^{11}$ The discrepancy might be explained by different outcome measures: we used objective measurement of physical activity and used weekends as a proxy for leisure time, whereas the studies included in the systematic review mainly relied on self-reports and the questions were specifically about leisure time. Our findings are in line with those of other studies using objective measures to compare persons with active versus sedentary jobs $^{30,35}$ or police officers versus higher-ranking police staff, ${ }^{22}$ which revealed differences in physical activity on working days, but not on non-working days.

The weekdays versus weekend day differences, where nonemployed participants and those in the low-level occupational category were less sedentary and more active during weekdays than on weekend days, while self-employed participants were more sedentary and less active on weekdays than on weekend days, are in accordance with some previous studies. Swiss workers in the moderate and high occupational intensity groups ${ }^{30}$ and Australian blue collar workers, technicians, and scientists ${ }^{28}$ were more active on weekdays than weekend days, while the opposite was reported for Swiss workers in low occupational intensity groups ${ }^{30}$ and office workers from the UK, ${ }^{15}$ Singapore, ${ }^{17}$ and Australia. ${ }^{8,20}$ Conversely, we found very few differences between weekdays and weekend days among those in the intermediate or high-level occupational categories, which is in agreement with studies among British office-workers, whether including both sexes ${ }^{16}$ or only women. ${ }^{18}$

Apart from differences between those in the low-level occupational category and the non-employed, the activity levels were fairly similar for non-employed and employed participants. This is contrast to several other studies using objective methods to assess physical activity. For example, in an American study, employed men were more active than non-employed healthy men, although such a difference was not found among women. ${ }^{35}$ Furthermore, employed people had a higher step count than unemployed persons in Belgium, ${ }^{36}$ and also when compared with homemakers and disabled persons in Finland. ${ }^{37}$ Additionally, British retirees were found to be less sedentary and more active than employed people. ${ }^{38}$ The differences between our findings and those of previous studies could be explained by the variety of subgroups included in our non-working category, with homemakers being less sedentary and more active than disabled and retirees. 

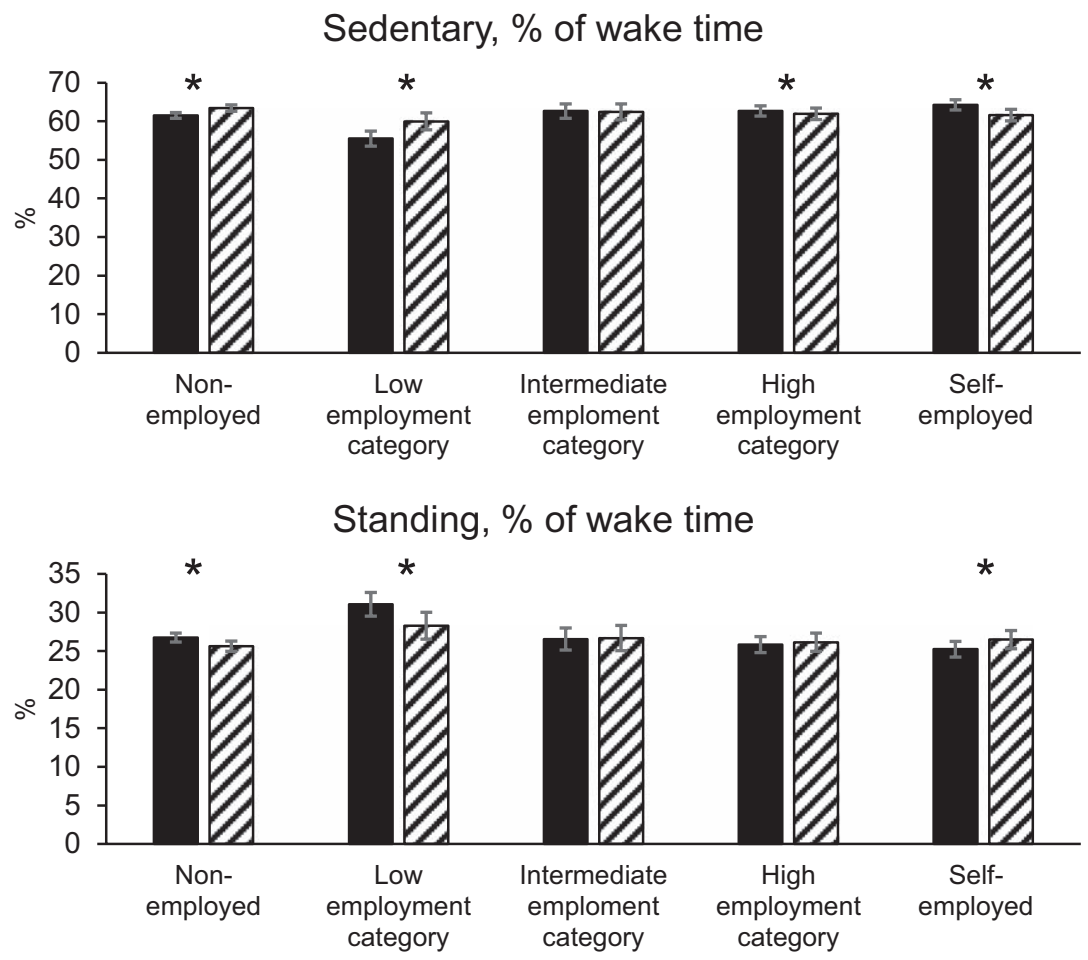

FIGURE 1. Percentage of waking time (95\% confidence interval) spent sedentary, standing, stepping and in higher-intensity physical activity, by employment status, on weekdays and weekend days. Solid bars represent \% of time on weekdays and hatched bars \% of time on weekend days. Statistically significant differences between weekdays and weekend days in each subgroup are marked with *.

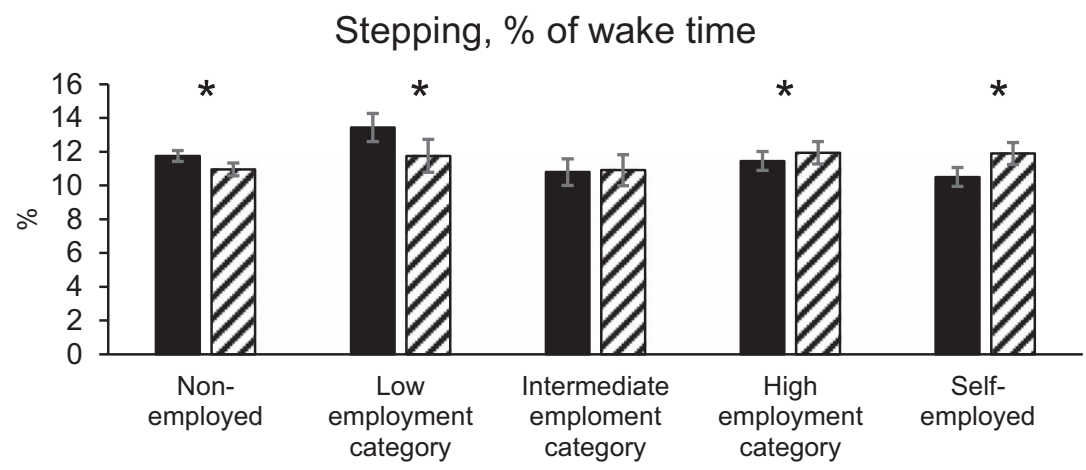

Higher physical activity, \% of wake time

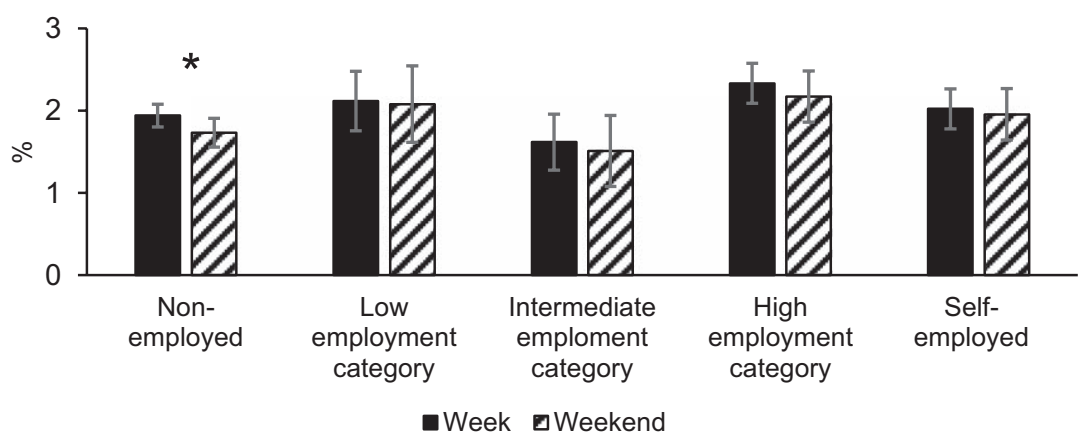

Strengths of this study include the objective measurement of both sedentary time and time spent at different activity levels, using a thigh-worn accelerometer, as well as the ability to distinguish between weekdays and weekend day activity levels, and the diverse study sample, which included a wide variety of occupational categories and non-employed people. Thigh-worn accelerometers provide reliable measurement of sedentary time, and enable distinguishing between sitting and standing time. ${ }^{39}$ Furthermore, accelerometers provide detailed information on activity over time, allowing comparison of activity between weekdays and weekend days. Including the non-employed resulted in a broader assessment of occupational category, although the currently non-employed could have been previously employed in many different occupational categories. 
TABLE 3. Percentage of Waking Time, With 95\% Confidence Interval (Cl), Spent Sedentary, Standing, Stepping, and in Higher-Intensity Physical Activity, on Average Days, for the Non-Employed. The Models have been Adjusted for Age, Sex, Presence of Diabetes, and Presence of Mobility Limitations

\begin{tabular}{|c|c|c|c|c|c|c|c|c|c|c|c|c|c|c|c|c|}
\hline \multirow{2}{*}{ Sedentary } & \multicolumn{3}{|c|}{$\begin{array}{c}\text { Retired } \\
(n=704)\end{array}$} & \multicolumn{3}{|c|}{$\begin{array}{c}\text { Homemaker } \\
(n=\mathbf{2 3 3})\end{array}$} & \multicolumn{3}{|c|}{$\begin{array}{l}\text { Disabled } \\
(n=136)\end{array}$} & \multicolumn{3}{|c|}{$\begin{array}{l}\text { Unemployed } \\
\quad(n=74)\end{array}$} & \multicolumn{3}{|c|}{$\begin{array}{l}\text { Rentier } \\
(n=53)\end{array}$} & \multirow[b]{2}{*}{$\boldsymbol{P}^{*}$} \\
\hline & $\begin{array}{c}\text { Mean } \\
62.9\end{array}$ & \multicolumn{2}{|c|}{$95 \% \mathrm{CI}$} & $\begin{array}{c}\text { Mean } \\
60.1\end{array}$ & \multicolumn{2}{|c|}{$95 \% \mathrm{CI}$} & $\begin{array}{c}\text { Mean } \\
63.6\end{array}$ & \multicolumn{2}{|c|}{$95 \% \mathrm{CI}$} & $\begin{array}{c}\text { Mean } \\
62.0\end{array}$ & \multicolumn{2}{|c|}{$95 \% \mathrm{CI}$} & $\begin{array}{c}\text { Mean } \\
64.0\end{array}$ & \multicolumn{2}{|c|}{$95 \% \mathrm{CI}$} & \\
\hline Standing & 25.9 & 25.2 & 26.6 & 28.1 & 27.0 & 29.2 & 25.2 & 23.8 & 26.6 & 27.1 & 25.2 & 29.0 & 24.7 & 22.7 & 26.7 & 0.001 \\
\hline Stepping & 11.2 & 10.8 & 11.6 & 11.8 & 11.2 & 12.5 & 11.1 & 10.4 & 11.9 & 11.0 & 9.9 & 12.0 & 11.3 & 10.2 & 12.5 & 0.43 \\
\hline HPA & 1.8 & 1.7 & 2.0 & 1.9 & 1.6 & 2.1 & 1.6 & 1.3 & 2.0 & 1.8 & 1.3 & 2.2 & 1.8 & 1.3 & 2.3 & 0.83 \\
\hline
\end{tabular}

HPA, higher-intensity physical activity.

${ }^{*} P$ value for overall differences between different employment status.

Weaknesses of the study include the use of self-reports of rather crudely defined employment status, which did not use any standardized occupational classifications. Also, we were not able to confirm working days or hours or domains of physical activity. However, the differences in activity levels between occupational categories were mainly observed on weekdays but not on weekend days, and this finding remained robust after we excluded those who reported shiftwork. This provides some evidence that weekdays and weekend days did represent typical working and non-working days, respectively, with sufficient precision. HPA was based on step frequency, which may be less precise than using acceleration to determine intensity levels. It has, however, been demonstrated that a step frequency higher than $\sim 110 \mathrm{steps} / \mathrm{min}$ equals a metabolic equivalent of task (MET) value of more than or equal to $3.0,{ }^{26}$ it may, therefore, be interpreted as an approximation of moderate-tovigorous physical activity. In addition, while our algorithm to automatically determine wake and bed time in 24-hour activPAL ${ }^{\mathrm{TM}}$ data could be used as an accurate measure to identify waking time, ${ }^{25}$ it may still have led to some misclassification between sleeping and sedentary time. About $25 \%$ of those who were offered the accelerometer were excluded from the analysis because of missing information. If anything, non-response could have weakened the association between occupational category and physical activity, given that those excluded were less educated than those included, and thus more likely to be non-employed or in the low-level occupational category. The participants of this study were Dutch people aged 40 to 75 years, which may limit the generalizability of the findings to other age groups and non-European populations.

\section{CONCLUSIONS}

We found that adults in the low-level occupational category were less sedentary and more active than those in higher-level occupational categories and those who were non-employed, especially on weekdays. However, we did not find evidence of participants in higher-level occupational categories being more physically active on weekend days than those in low-level occupational category. As physical activity or sedentary behavior can relate to different domains, that is, leisure time or work, it can have different health effects, and can be influenced by different types of interventions. For example, people who have a high-level occupational category are likely to have sedentary jobs and can benefit from workplace interventions, whereas people in the low-level occupational category and physically demanding work may need interventions focusing on leisure-time physical activity. In order to cover occupational physical activity and occupational sedentariness, which have to date scarcely been studied, future studies should combine objective physical activity and sedentary behavior measurements with accurate information on occupational category and actual working hours.

\section{REFERENCES}

1. Bauman AE, Reis RS, Sallis JF, Wells JC, Loos RJ, Martin BW. Correlates of physical activity: why are some people physically active and others not? Lancet. 2012;380:258-271.

2. Sallis JF, Bull F, Guthold R, et al. Progress in physical activity over the olympic quadrennium. Lancet. 2016;388:1325-1336.

3. Lee IM, Shiroma EJ, Lobelo F, et al. Effect of physical inactivity on major non-communicable diseases worldwide: an analysis of burden of disease and life expectancy. Lancet. 2012;380:219-229.

4. Rezende L, Lopes M, Rey-López J, Matsudo V, Luiz O. Sedentary behavior and health outcomes: an overview of systematic reviews. PLOS ONE. 2014;9:e105620.

5. Church TS, Thomas DM, Tudor-Locke C, et al. Trends over 5 decades in U.S. occupation-related physical activity and their associations with obesity. PLoS ONE. 2011;6:e19657.

6. Welk GJ, Kim Y. The context of physical activity in a representative sample of adults. Med Sci Sports Exerc. 2015;47:2102-2110.

7. Jans MP, Proper KI, Hildebrandt VH. Sedentary behavior in dutch workers. Am J Prev Med. 2007;33:450-454.

8. Parry S, Straker L. The contribution of office work to sedentary behaviour associated risk. BMC Public Health. 2013;13:296.

9. Gidlow C, Johnston LH, Crone D, Ellis N, James D. A systematic review of the relationship between socio-economic position and physical activity. Health Educ J. 2006;65:338-367.

10. Beenackers MA, Kamphuis CBM, Giskes K, et al. Socioeconomic inequalities in occupational, leisure-time, and transport related physical activity among european adults: a systematic review. Int J Behav Nutr Phys Act. 2012;9:116

11. Kirk MA, Rhodes RE. Occupation correlates of adults' participation in leisure-time physical activity: a systematic review. Am J Prev Med. 2011; 40:476-485.

12. Troiano RP, Berrigan D, Dodd KW, Masse LC, Tilert T, McDowell M Physical activity in the united states measured by accelerometer. Med Sci Sports Exerc. 2008;40:181-188.

13. Arias OE, Caban-Martinez A, Umukoro PE, Okechukwu CA, Dennerlein JT. Physical activity levels at work and outside of work among commercial construction workers. J Occup Environ Med. 2015;57: 73-78.

14. Kunst AE, Bos V, Andersen O, et al. Monitoring of trends in socioeconomic inequalities in mortality: experiences from a european project. Demogr Res. 2004;S2:229-254.

15. Clemes SA, O'Connell SE, Edwardson CL. Office workers' objectively measured sedentary behavior and physical activity during and outside working hours. J Occup Environ Med. 2014;56:298-303.

16. Smith L, Hamer M, Ucci M, et al. Weekday and weekend patterns of objectively measured sitting, standing, and stepping in a sample of office-based workers: the active buildings study. BMC Public Health. 2015;15:9.

17. Müller-Riemenschneider FB, Ng SHX, Koh D, Chu AHYM. Objectively measured patterns of activities of different intensity categories and steps taken among working adults in a multi-ethnic asian population. $J$ Occup Environ Med. 2016;58:e206-e211.

18. Kirk A, Gibson AM, Laverty K, Muggeridge D, Kelly L, Hughes A. Patterns of sedentary behaviour in female office workers. AIMS Public Health. 2016;3:423-431 
19. van Dommelen P, Coffeng JK, van der Ploeg HP, van der Beek AJ, Boot CR, Hendriksen IJ. Objectively measured total and occupational sedentary time in three work settings. PLoS One. 2016;11:e0149951.

20. Thorp AA, Healy GN, Winkler E, et al. Prolonged sedentary time and physical activity in workplace and non-work contexts: a cross-sectional study of office, customer service and call centre employees. Int J Behav Nutr Phys Act. 2012;9:128.

21. Umukoro PE, Arias OE, Stoffel SD, Hopcia K, Sorensen G, Dennerlein JT Physical activity at work contributes little to patient care workers' weekly totals. J Occup Environ Med. 2013;55(Suppl):S63-S68.

22. Ramey SL, Perkhounkova Y, Moon M, et al. Physical activity in police beyond self-report. J Occup Environ Med. 2014;56:338-343.

23. Steeves JA, Tudor-Locke C, Murphy RA, King GA, Fitzhugh EC, Harris TB Classification of occupational activity categories using accelerometry: NHANES 2003-2004. Int J Behav Nutr Phys Act. 2015;12:89.

24. Schram MT, Sep SJS, van der Kallen C, et al. The maastricht study: an extensive phenotyping study on determinants of type 2 diabetes, its complications and its comorbidities. Eur J Epidemiol. 2014;29:439-451.

25. van der Berg J, Willems PJB, van der Velde JHPM, et al. Identifying waking time in 24-h accelerometry data in adults using an automated algorithm. J Sports Sci. 2016;34:1867-1873.

26. Tudor-Locke C, Rowe DA. Using cadence to study free-living ambulatory behaviour. Sports Med. 2012;42:381-398.

27. Steele R, Mummery K. Occupational physical activity across occupational categories. J Sci Med Sport. 2003;6:398-407.

28. Miller R, Brown W. Steps and sitting in a working population. Int J Behav Med. 2004;11:219-224.

29. Schofield G, Badlands H, Oliver M. Objectively-measured physical activity in New Zealand workers. J Sci Med Sport. 2005;8:143-151.
30. Brighenti-Zogg S, Mundwiler J, Schüpbach U, et al. Physical workload and work capacity across occupational groups. PLOS ONE. 2016;11:e0154073.

31. Stringhini S, Sabia S, Shipley M, et al. Association of socioeconomic position with health behaviors and mortality. JAMA. 2010;303:1159-1166.

32. Platts LG, Head J, Stenholm S, Singh Chungkham H, Goldberg M, Zins M. Physical occupational exposures and health expectancies in a french occupational cohort. Occup Environ Med. 2017;74:176-183.

33. Heuch I, Heuch I, Hagen K, Zwart J. Physical activity level at work and risk of chronic low back pain: a follow-up in the nord-trøndelag health study. PLoS One. 2017;12:e0175086.

34. Harari G, Green MS, Zelber-Sagi S. Combined association of occupational and leisure-time physical activity with all-cause and coronary heart disease mortality among a cohort of men followed-up for 22 years. Occup Environ Med. 2015;72:617-624.

35. Van Domelen DR, Koster A, Caserotti P, et al. Employment and physical activity in the U.S. Am J Prev Med. 2011;41:136-145.

36. De Cocker K, Cardon G, De Bourdeaudhuij I. Pedometer-determined physical activity and its comparison with the international physical activity questionnaire in a sample of belgian adults. Res Q Exerc Sport. 2007;78: 429-437.

37. Hirvensalo M, Telama R, Schmidt MD, et al. Daily steps among finnish adults: variation by age, sex, and socioeconomic position. Scand J Public Health. 2011;39:669-677.

38. Godfrey A, Lord S, Galna B, Mathers JC, Burn DJ, Rochester L. The association between retirement and age on physical activity in older adults. Age Ageing. 2014;43:386-393.

39. Kozey-Keadle S, Libertine A, Lyden K, Staudenmayer J, Freedson PS. Validation of wearable monitors for assessing sedentary behavior. Med Sci Sports Exerc. 2011;43:1561-1567. 